\title{
Diffusing the Ubuntu Philosophy into E-Government: A South African Perspective
}

\author{
Hossana Twinomurinzi ${ }^{1}$, Jackie Phahlamohlaka ${ }^{2}$, and Elaine Byrne ${ }^{1,3}$ \\ ${ }^{1}$ Department of Informatics, University of Pretoria \\ Pretoria, South Africa \\ twinoh@up.ac.za \\ ${ }^{2}$ Defence, Peace, Safety and Security, Council for Scientific and Industrial Research \\ Pretoria, South Africa \\ jphahlamohlaka@csir.co.za \\ ${ }^{3}$ Department of Epidemiology \& Public Health Medicine, The Royal College of Surgeons in \\ Ireland, Dublin, Ireland \\ elainebyrne2@rcsi.ie
}

\begin{abstract}
Information Systems (IS) researchers are increasingly calling for contextual approaches to Information and Communication Technologies (ICT) innovations [1]. The call proceeds from the realization that ICT and egovernment policies are often adopted and developed with a blind focus on the ICT artifact, and with little reflection on the contribution of ICT to the context [2]. This paper emanates from an ethnographic study that investigated how ICT can facilitate government policy implementation in a development context. The study found it necessary to understand the role of tradition and its potential influence on ICT implementations in South Africa. The paper reviews the context of the South African government and its conspicuous inclination to the way of life, Ubuntu. Ubuntu is growing in popularity and is increasingly being applied as an African solution to African problems such as poverty, political strife and trade. Using Grounded Theory analysis, the findings revealed the critical importance of ICT not threatening tradition but rather complementing it, the role that ICT could play in enabling or enhancing community assemblies, and the marginalized role of women citing how ICT might be used as a means to empower rather than marginalize women even further. We conclude that e-government needs to be re-conceptualized in South Africa for a more culturally acceptable and relevant approach to the use of ICT innovations for development.
\end{abstract}

Keywords: Keywords: Policy Implementation, e-Government, ICT for Development.

\section{Introduction}

South Africa has one of the highest socio-economic income inequalities in the world having more than $43 \%$ living below the poverty line [3] and $23.6 \%$ unemployed [4]. Human development consequently underlies most of the government initiatives. Among the principal avenues identified towards achieving the development is through 
e-government [5]. South Africa's e-government policy identifies its four critical features as: interoperability (cross-functionality across different departments); ICT security (dealing with the security of government electronic systems and information); economies of scale (achieving this includes investments in research and development to developing local skills with the ability to produce internally), and: elimination of duplication (abolish unnecessary duplication of similar IT functions, projects and resources) [5]. South Africa has however been bold enough to admit that despite the open and active sponsorship and support for e-government, the expected benefits and development outcomes are yet to be fully realised [6].

IS researchers argue that such outcome challenges are often because the ICT initiatives fail to take into account the important contextual aspects of the implementation environment, and in many instances adopt overly deterministic business models [1]. The same conflict is seen in South Africa. The focus of the e-government policy, illustrated through the success factors, reflects this critique. The criteria indicate a technical and deterministic approach to e-government with an inadequate emphasis on the social and contextual nature of ICT.

This paper reports on findings from a project centred on creating an awareness of the Promotion of Administration Justice Act 3 of 2000 (PAJA) through the use of Group Support Systems (GSS). A GSS is a specialised type of ICT system designed to facilitate people working together towards a goal [7]. The PAJA seeks to overcome the historical apartheid injustices by empowering the public to expect from government a reasonable opportunity to make representations before receiving a negative decision (an administrative action), and to ask for written reasons and/or challenge the government.

\subsection{South African Government: Batho Pele}

With the fall of apartheid, South Africa enacted a new Constitution as the supreme law in 1996. The founding provisions of the new constitution are grounded in the values of "dignity, the achievement of equality and the advancement of human rights and freedoms, non-racialism and non-sexism, supremacy of the constitution and the rule of law and in universal adult suffrage" [8]. The new constitution called for a radical transformation in government from the previous apartheid style where government administrators made decisions without consultation to a more democratic style where decisions must be made in a more consultative manner. The government through the new constitution of 1996 has since brought into effect a number of policy reforms in an effort to "heal the divisions of the past and establish a society based on democratic values, social justice and fundamental human rights" [8].

Transformation formally began in 1995 with the White Paper on the Transformation of Public Service [9] hereafter abbreviated to WPTPS. The WPTPS established the institutional framework that would guide the introduction of new policies and the implementation of the new constitutional mandates. It was shortly followed in 1997 by the White Paper on Transforming Public Service Delivery, labeled as the Batho Pele White Paper [10]. The Batho Pele White Paper specifically aimed at creating a participative model of governance. The Batho Pele White Paper was adopted into policy in 2002 and branded Batho Pele. Batho Pele literally means "People First" and the resultant adage 'We belong, we care, we serve' became the belief set to guide the government. Batho Pele formally redefined the outlook of government to correspond more to the harmonious South African way of life, Ubuntu. 


\subsection{South African Way of Life: Ubuntu}

Ubuntu is an indigenous South African philosophy that comprehends individual existence as being inseparable from the collective through warm and filial relationships. Ubuntu is short for the Nguni proverb 'Umuntu ngumuntu ngabantu' which literally translated means "a person is a person through their relationship to others" [11]. The notion of Ubuntu subsumes an individual's personality, place and provision as having everything to do with the collective - we are who we are because we come from and belong to a certain collective. Any attempt to define Ubuntu in an English sentence reduces its deep indigenous meaning [12]. Ubuntu is an African awareness of being. The Ubuntu way of life is clearly an African collectivist philosophy which lies in sharp contrast to the more individualistic and self-centered Western way of life. The core values of Ubuntu are communalism, interdependence, humanness, sharing and compassion. Ubuntu does not imply that individual choice is lost and resigned to traditional leaders but means that traditional leaders carry the burden to express the choice of the individuals as a collective interest.

Batho Pele is an embodiment of the values of Ubuntu. The adage Batho Pele itself expresses the Ubuntu way of life in prioritizing the interests of the citizen according to the quality of life rather than on the neo-liberal basis of traditional economics.

\subsection{Linking ICT and Ubuntu}

During the PAJA project the social and contextual nature of ICT emerged as fundamental to understanding how e-government could support the emancipation of people from different forms of deprivation such as poverty, disease and oppression. The principle finding which facilitated this understanding was that citizens could easily understand the philosophical underpinnings of the government's over-arching policy of Batho Pele as it strongly correlates to the South African way of life, Ubuntu. However, the difficulty arose with linking the provision of multi-purpose centres or any other technologically enabled initiative to this policy. Once these ICT innovations were linked or an association was made with local traditions and culture the communities recognised the potential of ICT to their development and enthusiastically embraced these opportunities. Consequently this paper reflects on the question: Can e-government in South Africa support human-development by connecting ICT innovations to the South African philosophy of life, Ubuntu?

To provide the context to these findings this paper is structured accordingly. Section 2 reviews the literature on e-government and the diverse discourse about what human development means. Section 3 presents the research approach used to conduct the research, Grounded Theory. Section 4 presents the findings and the analysis. As required in Grounded Theory, we compare the findings with contemporary theory used in ICT for Development (ICT4D) discourse, Amartya Sen's Capabilities Approach, which argues for creating opportunities for development based on what people are able to do and to be. Section 5 presents the conclusions from the paper and the contributions to knowledge. 


\section{Literature Review}

\subsection{E-Government}

E-government is a popular field of research within IS without a commonly agreed upon definition but broadly understood as "the use of information technology to enable and improve the efficiency with which government services are provided to citizens, employees, businesses and agencies" [13]. In striving for the perceived benefits of e-government almost all governments around the world are enthusiastically embracing, or having e-government pressed upon them. High on the list of these perceived benefits are the promises of better governance, cost reduction and improved efficiency of government services [14]. E-government literature suggests that the transition from government to e-government exposes governments to opportunities to improve government practices through process redesigns [15]. The literature generally posits five stages of e-government evolution;

- One way communication where information flows from government in a single direction - out. An example would be the static information provided by a government website

- Two-way communication where information also flows back to government but no immediate response should be expected. An example is the typical contact us form on government websites

- Exchange where government has an active presence on the internet and is able to actively communicate back and forth with its clients as well as carry out online transactions. An example is filing tax returns and making the payments online.

- Portal is where the government establishes a single point of contact for all government offerings regardless of the services that may be required by its constituents. An example may be a citizens paying taxes and traffic bills from a single portal without realizing that the two payments are for two different government entities

- Political participation is where citizens may be able to vote online using the egovernment portal.

Many governments in adopting the utopian view have overlooked the fact that the strategies used in the private sector for customer satisfaction, retention and adoption cannot be directly applied to citizens. They quickly fall into the trap of treating citizens as business clients. There is a fundamental difference in that citizens have rights from government and duties to government while business clients have a choice [16]. Governments have a legal and moral responsibility to serve all the citizens and the different constituents within the country [15].

\subsection{Development and ICT4D}

One of the driving forces in government is 'development'. The nature of development is a subject of continuing theoretical debate [1] ranging from something that happens in the third world [17] to a structured and linearly staged process of enabling developing countries to catch up with developed countries [18]. There is, however, one underlying theme in the discourse on development; there is an urgent need to lift people (especially women and children) out of deprivation. Deprivation is more prominent in 
developing countries where many are dying of preventable illnesses, hunger and the like, not only because of any lack of knowledge but also because of the lack of means to deal with these problems [18].

A range of reasons have been offered as to why certain countries experience development and why others remain mired in poverty, unable to raise the standards of living, despite following the same prescripts: colonialism, globalisation, unequal trade agreements, the lack of democracy and religion [19].

Strategies on how to achieve development became a subject area of interest soon after the end of the Second World War and the subsequent creation of independent states. The discourse on development since that time gradually transformed in three significant periods: the 1950s, the 1960s, and the 1980s. The 1950's called for aggregative analytical frameworks proposing investment in modern activities and an emphasis on good planning, e.g. the big push [20] and the take-off sustained growth [21]. Those approaches did not yield much success. The 1960's saw the flawed argument that developing countries needed to emulate the key characteristics and stages of growth that developed countries had passed through to get to where they are [18]. From the 1980s to date the development discourse has gradually expanded to include individual information from household surveys such as the impact and role of health and education on development. Considering that South Africa was in a state of apartheid before 1994, all its development efforts have been based on the current approaches to development since the 1980's wave.

The discourse on ICT4D has followed closely behind development in a supporting and enabling role and is traced back to the 1950s where ICT was viewed as something that could automate government administrative functions. The main concern in ICT4D today, similar to development, is how to innovate ICT towards socioeconomic development amongst the billions of underprivileged people in the world. Avgerou [1] summarised the current discourse on ICT4D as falling along two continuums; how development occurs, and how ICT is innovated to contribute to the process of development.

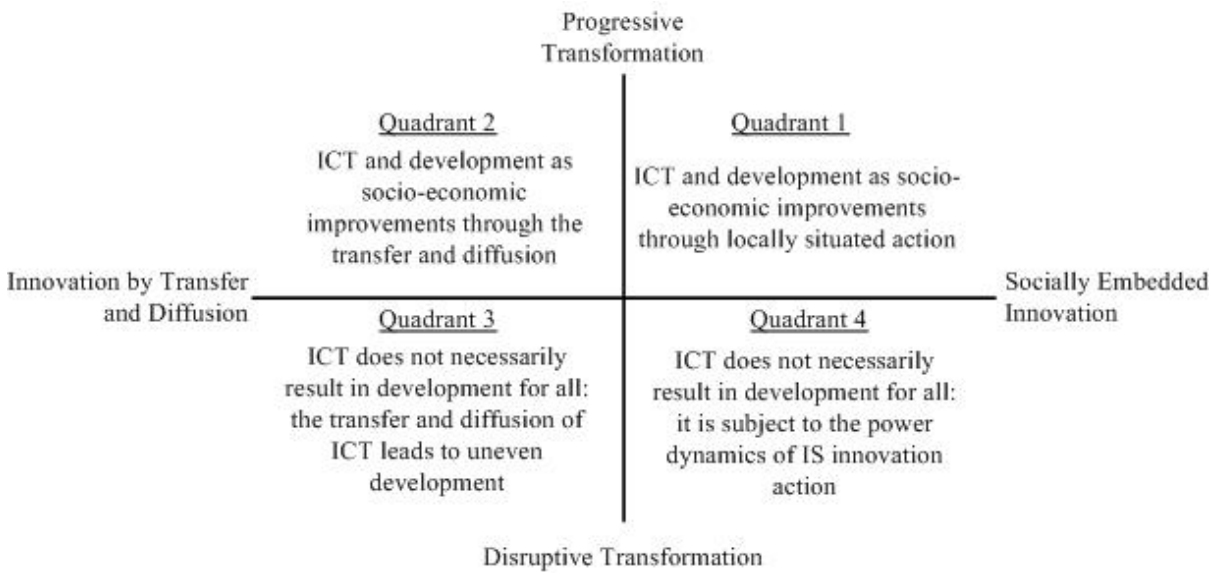

Fig. 1. Discourse on ICT4D [1] 
On one continuum, development ranges from occurring progressively at one end and disruptively at the other. Progressive development happens when development is accepted uncritically. Disruptive development happens when the development is accompanied by fundamentally different norms from existing ones and may require substantial changes in social and individual behaviour. On the second continuum, on the one hand ICT is innovated to contribute to the process of development where it is transferred and diffused from developed to developing countries. On the other hand, ICT is adapted from within the social context of the developing country. Avgerou (2009) combined the two influences to result in four quadrants (Fig. 1).

In quadrant $1, \mathrm{ICT}$ is innovated with a view to improve life conditions from within the local context, taking into account the embedded historical, cultural and social meaning. Quadrant 2 adherents suggest that it is possible to create an ICT tool which is modeled using best-practices. It is argued that such a model is then able to work across all situations and bring about development as seen in the 'best-practice' literature. In quadrant 3, ICT is at times implemented but only benefits a select few. The discourse here questions the power relations that exist in society and how these powers may be carried over when new ICT is implemented. Quadrant 4 demonstrates how ICT is accepted as a force of socio-economic change, but one that brings with it power relations. ICT in this sense in fact leads to greater levels of domination and inequality hence extending the socio-economic and digital divide.

South Africa's approach to e-government fits in quadrant 2 in its prescriptive approach that assumes an ICT model derived from technical business best-practice can quickly be diffused across the diverse segments of government. That model does not take into account the context of South African government with its very strong inclination to Ubuntu. Based on the Ubuntu inclination, South Africa's e-government approach should position itself in quadrant 1 . This paper argues that for a fit with quadrant 1 a fundamentally different approach to ICT is needed in e-Government in South Africa.

\section{Research Approach}

This paper emanates from one of the author's ethnographic immersion in a research project entitled 'Enabling access to human rights through thought processes and webbased Group Support Systems (GSS) tools'. As the author progressed through the PAJA project and reviewed literature on Development, ICT4D and e-government, four issues stood out:

- Development is dependent upon the perspective which is adopted e.g. traditional economists consider development as an indicator of Gross Domestic Product while others consider it as the freedom to make choices [1,22]

- There is a rapidly growing demand for ICT4D theory and inquiry, as evidenced by the rise in academic and practitioner conferences and/or journals with either a special track or entire publication dedicated to ICT4D [23]

- Consistent with ICT4D, there are dangers and problems that have resulted from developing countries blindly adopting IS approaches which have worked in developed countries $[24,25]$. 
- African developing contexts are characterized by the collectivist nature of society [12]. The collectivist culture is largely ignored when researching African environments yet is critical to understanding the contextual process of ICT implementations towards human development [26]. The collectivist nature, called Ubuntu, surfaces strongly in South Africa's approach to government Batho Pele.

The thoughts culminated into seeking to develop an explanatory theory or framework that could account for how e-government could be harnessed contextually in the spirit of Ubuntu to lead to improvements in human development. Ethnographers refer to such thoughts as the 'grand' research question because it is deliberately wide and not hedged in with firm hypotheses, research designs, sub-questions and instruments [27]. As the PAJA project progressed the researcher clarified the grand research question delimiting its scope and internal structure into the finer primary research question: How could ICT be used to facilitate policy implementation in a human development context?

Three field locations were enrolled as research sites for the PAJA project in 2005 and over three years generally maintained the same 46 research participants. Lebotloane is in the North West Province and the research was hosted by Lerethlabetse Multi Purpose Community Centre (now called the Lerethlabetse Thusong Service Centre); Siyabuswa is in the Mpumalanga Province and the research was hosted by the Siyabuswa Education Improvement and Development Trust (SEIDET); and the University of Pretoria is in the Gauteng Province and the research was hosted by the Department of Informatics. The common denominator in selecting the research sites was a solid institutional base and the availability of computers. Since the PAJA project was a longitudinal research project, cross-institutional linkages could provide better grounds for long term sustainability and such institutions are usually already established within their communities. Since the limited research funding did not include for the provision of computers it meant that the host institutions needed to have an existing computer infrastructure.

The research at each site was carried out in a workshop setting. The purpose of the workshops was to raise awareness about the process involved in the implementation of the PAJA. The workshops were designed to demonstrate the possibilities for the use of ICT (particularly GSS) to support the PAJA process simulated using case scenarios. Over the period 2005 to 2008 , one workshop was held at each site every year, making a total of nine workshops over the three years. The workshops each year were always planned so that we completed the three sites within a month. Data was collected at every workshop activity using different data collection instruments.

The rich ethnographic data from the observations, electronic logs, videos, questionnaires, interviews and field visits during the project were analysed using Grounded Theory to develop a substantive theory that could explain how ICT could be used to facilitate policy implementation in the spirit of Ubuntu. Additional information on the influence of Ubuntu on daily life was obtained from structured interviews conducted with six research participants from three different regions of South Africa, four of who were from rural areas and two from urban areas. Two of the people from the rural areas are community leaders while one of those from the urban area is from a royal family. The interview questions were derived from Whitacre's [28] literature on customs and tradition which seeks to understand the role of tradition as a set of customs, beliefs and practices, and the influences that tradition wields. 
Grounded Theory (GT) techniques have been shown to be helpful when attempting to create theory from data, rather than data emerging from theory [29]. Kelle [30] refers to the divergent approaches on how to conduct Grounded Theory as a conflict between whether categories emerge or are forced out from empirical data. The paper adopts Strauss and Corbin's approach [31] since we were already guided by the context. Their approach starts with open coding where concepts that fit the data are produced. It is followed by axial coding where the derived concepts are investigated for causal relationships. Analytical memos are created during axial coding which form the basis of selective coding. The memos are the researcher's record of analysis and perceptions for further data collection. It ends with selective coding where an assumed core category is selected and related to the other categories systematically into a substantive theory. The obligation of Grounded Theory to engage the substantive theory that emerges from the findings with formal theory [31] is done in Section 4 using Amartya Sen's Capabilities Approach.

Grounded Theory emerges from the symbolic interactionist view of human behaviour [32] which posits that people assign meaning based on social interactions, which meaning is handed down and modified from generation to generation. Generalization in qualitative studies such as this is made against theory and not against populations making qualitative generalizations more analytical than statistical as may be the case in quantitative studies [33]. Hence data obtained from structured interviews from six research participants who are positioned to comment on their customs and traditions is sufficient for analysis if the bias of the researcher can be made explicit.

\section{Analysis and Findings}

The findings from the PAJA project that were significant in terms of the need to diffuse the Ubuntu philosophy as part of an e-government approach in South Africa were:

- The importance of entry into research sites through local leadership in terms of acceptability and sustainability of ICT projects. If local leaders (traditional and/or community leaders) introduce a group favourably, it almost guarantees acceptance and support by the community members

- The use of mediators on the computers in the communities is acceptable and appreciated. For example, one person used the computer for others who did not have the computer skills and that this was replicated outside the workshop as well

- Women were very active and felt comfortable in sharing opinions and views. Due to anonymity (and maybe the context) there did not seem to be any discrimination between comments from men or women. Though this could be because these were simulated scenarios, it still shows potential

- There was fairly good rapport between government administrators who were present and others. This showed that most service delivery problems are probably not due to any personal animosity but rather communication and understanding processes and procedures. 


\subsection{Traditional Practices}

Tradition plays a very important role in all South African cultures in relation to Ubuntu. The research participants all expressed great respect and reverence for their traditions and cultures. The comments below typify the sentiment:

- "They highly respect their traditional leaders as they remind and help them to practice and respect their tradition."

- "They highly honour their culture, for example boys and girls still go to initiation school where they are taught about their culture in both communities (Sotho \& Ndebele)."

Children grow up hearing about their traditional cultures and beliefs and how they are played out in daily life. An upbringing in cultural values applies both to the people who live in the urban areas and those who live in rural areas. The strong respect people have for culture and tradition is reflected in the popularity of initiation schools and shows the tensions that exist between modernization and development. For example, attendance at initiation schools, though optional, is considered of such great importance that if a person, male or female, has not gone to initiation school, the person will be despised within the community and be seen as a social misfit.

- "We grow up seeing these beliefs done and talked about that when we grow up we make it a point that we do the same that was done and then pass them on to other people. Initiation school for example is a strong belief in the Siyabuswa community that when a person has not gone to the school he/she would be discriminated on until he/she goes to the school."

At initiation school, the youth are ushered into their traditional customs and are taught some of the 'secrets' of their culture. Initiation school creates a very strong rite of passage into adulthood. Many youths choose to attend initiation schools even when a number of young adults lose their lives each year due to harsh conditions, such as spending days in cold weather, or through unsanitary practices, such as sharing knives for circumcision. However, many of the older traditions have been modernised, such as circumcision increasingly being conducted in hospital, whilst maintaining the initiation schools in terms of the cultural importance of such a rite of passage and the ceremonies around it. During the initiation school's rite of passage one of the most important cultures that is handed down is the spirit of oneness among people - the spirit of Ubuntu.

\subsection{Tensions between Modernization and Tradition}

As described in the popular African literature Things Fall Apart [34] and Heart of Redness [35] modernization raises tensions between traditions handed down over many generations and new modernized culture driven by ICT or different forms of authority. For example, some of the research participants noted that they hold dear their allegiance to the traditional leaders and their authority but are more cognizant of the greater government authority.

- "...there are also those who do not have respect."

- "They have a little respect to traditional leadership as most of them respect modern or local council." 
Traditionally, decisions that affect the community at large are taken collectively. Community meetings (Imbizos) are called and the case for and against the issue are made. Through traditional structures, community members can air their opinions and concerns. This is in keeping with the spirit of Ubuntu or collective personhood and collective morality [12] which is a fundamental concept in most African societies. Principles of continuous consultation and consensus, the use of ceremonies to express meaning and the need for spiritual and individual reflection are all principles on which the concept of Ubuntu is based. There are also other reasons why people choose to come together within communities, such as social reasons, such as funerals and marriages; religious reasons, mainly church; community meetings, e.g. concerning rising cases of thefts, unemployment; and political reasons, the African National Congress (ANC) as the biggest party in South Africa holds regular meetings and draws big crowds. The choice to attend meetings is usually optional or may be on invitation only, such as political or traditional meetings.

Community meetings are usually dominated by a few people, such as the elders or leaders, at times leaving the ordinary people feeling that the decisions that are adopted do not reflect their individual and collective preferences. At other times, the ordinary people feel that their leaders to whom they have given the responsibility for carrying out the groups decisions either distort them or are corrupted along the way. Minority groups such as women and youths very rarely have a direct voice in these meetings and if they desire to express themselves usually must resort to using the medium of men they know. In the traditional meetings, women generally only play an advisory role.

- "They feel that information is being distorted from them and the service is not delivered."

- "We the sisters will always play an advisory role at the back."

Regardless of the nature of meeting, the means of communicating at such an assembly is through loud speakers booming from a car driving through the streets of the community, word of mouth, the use of flyers and posters in streets, community radio stations, phones and through school outlets. More recently mobile phones are increasingly becoming a preferred method of communication.

\subsection{Discussion}

Traditional practices are strong and any ICT innovation needs to embrace the role of leaders and their inclusion in a communal approach. E-government in South Africa needs to adopt a more embracive approach that addresses the technical aspects of ICT innovations as evidenced in the e-government policy, but in a contextualised sociotechnical manner. Collaborative ICT has the potential to address previous inequities and enable all voices to be heard, as well as provide a means for leaders and government administrators to hear these voices. The approach to e-government needs to consider a holistic approach where all the people, including the women, are able to express themselves through their own traditional means in a spirit of Ubuntu, rather than through means imposed by external agents [18].

ICT needs to be viewed as tools than enhance the collective spirit and not simply for use by individuals with skills. Those with skills can acceptably act as mediators. Such an approach to e-government is similar to Amartya Sen's [36] views on development which centres on choice and the freedoms for people to make the 
choices they desire. Sen's [36] views on development have significantly influenced the United Nations approach to development and echo many of the features of Ubuntu and this is reflected in his Capabilities Approach to development. Sen [36], contends that the assessment of well-being should be concerned with an individual's capability to function, which he regards as "what a person can do or can be", and the real opportunities that the person has especially compared with others. The Capabilities Approach (CA) assesses individual well-being and social arrangements based on what individuals are able to do and to be. The basic premise is that by enlarging the choices available to individuals they can live the life they choose. In CA it is not enough to only remove obstacles that inhibit individuals from living the life they value; individuals should be provided with the means to achieve such a life.

In relation to e-government, CA illustrates that for development the existence of opportunities does not necessarily mean they can be drawn upon and utilised. For example, the South African government is in the process of rolling out ICT facilities in what are known as Thusong Service Centres (TSC) (formerly called multi-purpose community centres) where individuals have the opportunity to collaboratively interact with the government through channels such as the Internet and e-mail. In reality, these opportunities cannot be drawn upon because both the government administrators and the citizens do not know how to use the Internet or e-mail. As such, the real value of the ICT facilities as a development commodity within the TSCs does not exist. Sen [36] further advocates that commodities are desired for their characteristics rather than for their intrinsic value. Using the example of the Internet facilities within the TSCs, the Internet facilities can be used for different purposes such as interacting with government, self-help improvement programmes, for business or even as a social communicator. Owning or having a commodity does not necessarily mean that the owner will use all the features or abilities of the commodity or use them for a certain purpose. For example, as shown above, the internet facilities in the TSCs are not used to interact with government and yet are designed to be "one-stop centres providing integrated services and information from government, to communities close to where they live as part of a comprehensive strategy to better their lives" [37]. The success criteria outlined in the e-government policy assumes that ICT is desired for its intrinsic value. Government should reflect and be explicit about how ICTs can be used to achieve its development outcomes. It would mean changing the e-government policy to reflect the same development inclinations as government or making explicit how the suggested technical criteria will lead to development.

Additionally, the well being of a person is determined by what the individual succeeds in doing with the commodities and the characteristics of the commodities - a notion Sen [36] terms as functionings. A functioning is defined as "an achievement of a person: what he or she manages to do or be". A functioning must be distinguished from owning the good and the characteristics of the good as well or having utility in the form of happiness from that functioning. Functionings can hence be seen as features of a commodity and not the commodity. Consequently, for e-government to meaningfully contribute to development, government must assist people to use the facilities which are available. Collaborative ICT in its ability to facilitate groups of people to work together is able to play such a role between groups of people on one end and government administrators on the other end. In areas and instances where 
computer skills are limited, it is possible for the groups to use one mediator acting on behalf of the group.

Examining e-government as the development of people's capabilities, through providing the means to achieve (ICT innovations), but also the freedom to achieve (the skills, resources and environment), entails re-conceptualising e-government. Freedom to achieve is contextual and in South Africa involves a communal, rather than an individualistic, view of development. Collaborative ICT has the potential of addressing some of the cultural inequities through facilitating a more inclusive spirit in community assemblies and in enabling all voices to be heard.

\section{Conclusions}

E-government can be re-conceptualized to provide a more contextualized approach which will be more culturally relevant. The implications of this re-conceptualization are:

- A focus more on what can be done with the ICT, rather than the intrinsic value of ICT

- The use of mediators and collaborative ICT to expand capabilities of the collective

- Ability to address inequities persistent in traditional practices in a culturally sensitive way

- Revising the 'success factors' of e-government to alternatively use 'the means to achieve', 'the freedom to achieve' and 'achievement'

Batho Pele is an embodiment of the values of Ubuntu. The evident misalignment between the deterministic South African approach to e-government and the living reality of a government inclined towards development can be overcome by adopting an approach which is consistent with the spirit of Ubuntu.

\section{References}

1. Avgerou, C.: Discourses on Innovation and Development in Information Systems in Developing Countries' Research. In: Byrne, E., Nicholson, B., Salem, F. (eds.) Proceedings of the 10th International Conference on Social Implications of Computers in Developing Countries. Dubai School of Government, International Federation for Information Processing, Dubai, United Arab Emirates, p. 510 (2009)

2. Heeks, R., Bailur, S.: Analyzing e-government research: Perspectives, philosophies, theories, methods, and practice. Government Information Quarterly 24, 243-265 (2007)

3. The Presidency: Development Indicators: Mid-Term Review. The Presidency, South Africa, Pretoria (2007)

4. Statistics South Africa: Latest Key Indicators, Statistics South Africa, Pretoria, vol. 2009 (2009) (StatsOnline)

5. Republic of South Africa: Electronic Government: The Digital Future - A Public Service IT Policy Framework. In: Administration, D.o.P.S.a. (ed.) Department of Public Service and Administration, pp. 1-25 (2001)

6. Harris, L.: SITA calls on private sector for help. Computing SA, 10-11 (November 2006) 
7. Dennis, A.R., Wixom, B.H., Vandenberg, R.J.: Understanding Fit and Appropriation Effects in Group Support Systems via Meta-Analysis. MIS Quarterly 25, 167-193 (2001)

8. Republic of South Africa: Constitution of the Republic of South Africa, 1996. vol. 2008. South African Government Information (2008)

9. Republic of South Africa: White Paper on the Transformation of Public Service. In: South African Government Information (ed.). Government Printers (1995)

10. Republic of South Africa: White Paper on Transforming Public Service Delivery (Batho Pele White Paper). In: Administration, D.o.P.S.a. (ed.), vol. 388, p. 34. South African Government Gazette (1997)

11. Swanson, D.M.: Ubuntu: An African contribution to (re)search for/with a 'humble togetherness'. Journal of Contemporary Issues in Education 2, 53-67 (2007)

12. Mbigi, L.: Ubuntu. The African Dream in Management. Knowledge Resources (Pty) Ltd. (1997)

13. Carter, L., Belanger, F.: The utilization of e-government services: citizen trust, innovation and acceptance factors. Information Systems Journal 2005, 5-25 (2005)

14. UNCTAD: Using ICTs to Achieve Growth and Development. Trade and Development Board: Commission on Enterprise, Business Facilitation and Development. Expert Meeting in Support of the Implementation and Follow-up of WSIS: United Nations, Geneva, Switzerland (2006)

15. Davison, R.M., Wagner, C., Ma, L.C.K.: From government to e-government: a transition model. Information Technology \& People 18, 280-299 (2005)

16. Belanger, F., Hiller, J.S.: A framework for e-government: privacy implications. Business Process Management Journal 12, 48-60 (2006)

17. Chari, S., Corbridge, S.: The development reader. Routledge, London (2008)

18. Cypher, J.M., Dietz, J.L.: The process of economic development. Routledge, London (2009)

19. Secondi, G.: Economic Growth, Economic Development, and Human Development. In: Secondi, G. (ed.) The Development Economics Reader, xxiv, 555 p. Routledge, London (2008)

20. Rosenstein-Rodan, P.: Problems of Industrialization of Eastern and South-Eastern Europe. Economic Journal 53, 202-211 (1943)

21. Rostow, W.W.: The Take-Off Into Sustained Growth. Economic Journal 66, 25-48 (1956)

22. Byrne, E., Jolliffe, B.: Free and Open Source Software - Development as Freedom? In: Silva, L., Westrup, C., Reinhard, N. (eds.) Proceedings of the 9th International Conference on Social Implications of Computers in Developing Countries. IFIP TC 9 - WG 9.4, Sao Paolo, Brazil (2007)

23. Avgerou, C.: Information systems in Developing Countries: a Critical Research Review. Journal of Information Technology 23, 133-146 (2008)

24. Kanungo, S.: On the emancipatory role of rural information systems. Information Technology \& People 17, 407-422 (2004)

25. Wade, R.H.: Bridging the Digital Divide: New Route to Development or New Form of Dependency? Global Governance 8, 443-466 (2002)

26. Hofstede, G.: Culture's Consequences. Sage, Beverly Hills (1980)

27. Atkinson, P., Coffey, A., Delamont, S., Lofland, J., Lofland, L.: Editorial Introduction. In: Atkinson, P., Coffey, A., Delamont, S., Lofland, J., Lofland, L. (eds.) Handbook of Ethnography, xviii, 507 p. Sage, London (2001)

28. Whitacre, R.A.: Johannine polemic: the role of tradition and theology. Scholars Press, Chico Ca (1982) 
29. Willis, J.: Foundations of qualitative research: interpretive and critical approaches. Sage Publications, Thousand Oaks (2007)

30. Kelle, U.: "Emergence" vs. "Forcing" of Empirical Data? A Crucial Problem of "Grounded Theory" Reconsidered. Forum: Qualitative Social Research 6 (2005)

31. Strauss, A.: Qualitative Analysis for Social Scientists. Cambridge University Press, New York (1987)

32. Coyne, I.: Grounded Theory. School of Nursing \& Midwifery, pp. 1-27. Trinity College Dublin, Dublin (2009)

33. Lee, A.S., Baskerville, R.L.: Generalizing Generalizability in Information Systems Research. Information Systems Research 14, 221-243 (2003)

34. Achebe, C.: Things fall apart. Heinemann, London (1962)

35. Mda, Z.: The heart of redness. Oxford University Press, Oxford (2000)

36. Sen, A.K.: Development as freedom. Oxford University Press, Oxford (1999)

37. Republic of South Africa: Thusong Service Centre: Business Plan 2006 - 2014. vol. 2007. Government Communication and Information System (2007) 